\title{
Severity of cough in idiopathic pulmonary fibrosis is associated with MUC5 B genotype
}

Mary Beth Scholand ${ }^{1 *}$, Roger Wolff², Peter Fredrick Crossno ${ }^{1,3}$, Krishna Sundar $^{1}$, Molly Winegar ${ }^{1}$, Spencer Whipple ${ }^{1}$, Patrick Carey ${ }^{1}$, Nicholas Sunchild ${ }^{4}$ and Hilary Coon $^{5}$

\begin{abstract}
Background: A polymorphism (rs35705950) in the promoter region of the mucin MUC5B is associated with both familial and sporadic forms of idiopathic pulmonary fibrosis. (IPF) We hypothesize that this common MUC5B variant will impact the expression of cough, a frequent disabling symptom seen in subjects with IPF.

Methods: We genotyped 136 subjects with IPF. All living subjects were provided with a Leicester Cough Questionnaire (LCQ) to measure cough severity. We assessed allele effects of the MUC5B polymorphism on the LCQ scores using SAS General Linear Models (GLM) in the patients with IPF.

Results: In the 68 of the total 136 IPF patients who returned the LCQ, MUC5B minor allele frequency (T) is consistent with prior published studies (31\%). We found a significant independent effect of the T allele on the LCQ score ( $p=0.002$ for subjects with IPF). This effect is independent of other common causes of cough, including gastroesophogeal reflux disease and upper airway cough syndrome.

Conclusions: Cough severity, a common disabling phenotypic component of IPF, is significantly associated with the presence of the minor allele of a MUC5B promoter polymorphism. This study highlights a possible genetic mechanism for phenotypic heterogeneity in pulmonary fibrosis.
\end{abstract}

\section{Main text Introduction}

The Interstitial Lung Diseases (ILDs) are a heterogeneous group of lung diseases that result in progressive pulmonary functional decline and death. Idiopathic pulmonary fibrosis (IPF) is the most common idiopathic ILD, with an estimated 100,000 Americans affected. Current theory suggests that fibrotic lung disease occurs when genetically susceptible individuals are exposed to environmental triggers. Recently, a common variant in the promoter region of the mucin 5B (MUC5B) gene [1] was found to be associated with the development of idiopathic pulmonary fibrosis as well an increased production of MUC5B, an airway mucin.

Cough is a prominent but not universal symptom in patients with IPF. Cough is estimated to be present in $84 \%$ of patients with IPF and is more prevalent in

\footnotetext{
* Correspondence: scholand@genetics.utah.edu

'Division of Pulmonary Medicine, Department of Internal Medicine, University of Utah School of Medicine, 420 Chipeta Way, Suite 2020, Salt Lake City, UT 84108, USA

Full list of author information is available at the end of the article
}

patients who have never smoked or have more advanced disease [2]. IPF related cough can be extremely debilitating with detrimental impact on quality of life [3]. Moreover, in IPF, cough is an independent predictor of disease progression [2]. While the etiology of cough in a patient with IPF can be attributed to many causes and a thorough investigation is warranted [4], often the IPF itself is ultimately determined to be the primary cause for cough.

The etiology of cough attributed to IPF is not clear. There may be mechanical factors at play including destruction of the cough inhibitory fibers as the lung is distorted with the fibrotic process [5]. Studies have demonstrated that patients with IPF and ILD associated with systemic sclerosis have increased cough sensitivity [6]. We hypothesize that the minor allele of the MUCB promoter polymorphism (rs35705950), associated with increased mucin production, correlates with a clinical phenotype of IPF characterized by a more severe cough.

Ciomed Central

of the article

(c) 2014 Scholand et al.; licensee BioMed Central Ltd. This is an Open Access article distributed under the terms of the Creative Commons Attribution License (http://creativecommons.org/licenses/by/2.0), which permits unrestricted use, distribution, and reproduction in any medium, provided the original work is properly credited. The Creative Commons Public Domain Dedication waiver (http://creativecommons.org/publicdomain/zero/1.0/) applies to the data made available in this article, unless otherwise stated. 


\section{Methods and materials Study subjects}

Subjects were recruited from ongoing University of Utah ILD studies between 2005 and 2012. The diagnosis of IPF was established utilizing current diagnostic criteria $[7,8]$. This study was approved by the University of Utah Institutional Review Board (\#00031215). All subjects provided a written informed consent for participation.

\section{Measurements}

Subjects were given the Leicester Cough Questionnaire (LCQ) [9]. This questionnaire provides a total cough intensity score and three subscales measuring physical, psychological, and social impacts of cough [9]. As specified in Birring [9], items for each scale were summed and divided by the total number of items endorsed by the scale. The total score is the sum of the scale scores and ranges from $0-21$.

Comorbid conditions known to cause cough were determined by chart review and by personal interview when possible. These conditions include smoking status and history, use of ACE inhibitors, evidence of upper airway cough syndrome (UACS; none, possible, or definite), history of sleep apnea, and gastroesophogeal reflux disease (GERD). In addition, spirometry measuring forced vital capacity (FVC) and Forced Expired Volume in one second (FEV1) and diffusion capacity (DLCO) was performed utilizing standard methodology [10].

\section{Genotyping}

Genotyping was performed using a commercially available TaqMan assay; rs35705950 (MUC5b) according to the manufactures methods (Applied Biosystems, Foster City, CA). Each 5 ul PCR reaction contained $20 \mathrm{ng}$ of genomic DNA, primers, probes, TaqMan Universal PCR Master Mix (containing AmpErase UNG, AmpliTaq Gold enzyme, dNTPs, and reaction buffer). PCR was carried out under the following conditions: $50^{\circ} \mathrm{C}$ for 2 minutes to activate UNG, $95^{\circ} \mathrm{C}$ for $10 \mathrm{~min}$, followed by 40 cycles of $92^{\circ} \mathrm{C}$ for $15 \mathrm{sec}$, and $60^{\circ} \mathrm{C}$ for 1 minute using a 384 well dual block ABI 9700. Fluorescent endpoints of the TaqMan reactions were measured using a $7900 \mathrm{HT}$ sequence detection instrument.

\section{Analyses}

Chi-square test, $T$-test, and Fisher's exact test were used to compare diagnostic subgroups within our sample for demographic characteristics and the rs35705950 minor allele frequencies. We used SAS General Linear Models (GLM) to test for association between the LCQ scale scores and MUC5B genotype within the IPF group, first employing a full model including all the secondary covariates listed above, in addition to age, gender, and IPF status. Any subject with a missing value on any predictor was not included in the analysis. From these analyses, we report allele effects on questionnaire scales independent of these other model effects, and also total variance $\left(R^{2}\right)$ explained by the model. We then employed a parsimonious model including only predictors that were significant in the full model. We compared total variance by the full model to variance explained by the parsimonious model to explore the relative contribution of the additional predictors and the potential loss of statistical power due to missing data across all the predictors in the full model.

\section{Results}

\section{Descriptive results}

A total of 136 subjects with IPF were genotyped for the MUC5B SNP rs35705950. At the time of our study, 45 subjects had already died. 68 living subjects returned the LCQ.

Table 1 shows the descriptive characteristics of the subset of 68 IPF cases for whom LCQ scores were available. The population was male dominant $(61.76 \%(42 /$ $68)$ ) and mean age was 74.41 (standard deviation $=8.01$ ). The demographics of subjects who did not return the questionnaire were $67.6 \%$ male $(46 / 68)$ with a mean age of 76.16. The two groups (with and without questionnaire) are age and sex matched with a chi-square of 0.39 and a t-score of 1.49 respectively. All subjects had a diagnosis of IPF by ATS/ERS criteria.

Amongst the 68 patients with LCQ data, $71.64 \%$ of the subjects endorsed a history of GERD. All subjects with GERD reported treatment with proton pump inhibitors. A smaller percentage of patients reported a history of known UACS and were treated with a variety of therapies including nasal steroids and antihistamines, mostly

\section{Table 1 Qualitative phenotypes of 68 IPF cases who completed the LCQ questionnaire and were genotyped for MUC5B rs35705950}

\begin{tabular}{ll}
\hline Qualitative variable & \% subjects; IPF (N = 68) \\
\hline Male & $61.76 \%(42 / 68)$ \\
GERD (yes/no) & $71.64 \%(48 / 67)$ \\
Definite UACS & $32.81 \%(21 / 64)$ \\
Definite or possible UACS together & $42.19 \%(27 / 64)$ \\
Ever smoked & $35.82 \%(24 / 67)$ \\
Sleep apnea & $32.84 \%(22 / 67)$ \\
ACE inhibitor & $14.93 \%(10 / 67)$ \\
rs35705950 genotype frequencies & TT: $4.41 \%(3 / 68)$ \\
& GT: 63.24\% (43/68) \\
rs35705950 T allele frequency & GG: 32.35\% (22/68) \\
\hline
\end{tabular}

IPF - Idiopathic Pulmonary Fibrosis. GERD - gastroesophogeal reflux disease. UACS - Upper Airway Cough Syndrome. 
on an intermittent basis. Only $35.82 \%$ of the patients reported a history of smoking. None were current smokers.

The mean FVC and FEV1/FVC demonstrated restrictive disease as expected. The DLCO was reduced. This is summarized in Table 2. FVC and FEV1/FVC were entered as predictors in two separate full models because the use of FVC in defining FEV1/FVC results in multicollinearity if both are entered together as predictors in the same model [11]. In each of these full models, the FVC, the FEV1/FVC nor the DLCO were significant predictors of the cough measures, and the significance of other predictors in the model were not substantively different in comparing one full model to the other. Of the 68 subjects for whom we did not have LCQ responses, the mean FVC was $63.89 \%$ predicted $(s d=21.59)$. This score is statistically significantly lower $(\mathrm{t}-2.34, \mathrm{p}=0.02)$ than the group who answered the questionnaire, likely reflecting accrual of these patients at the end stage of their diseases.

The mean total LCQ score was 16.16 with a range of 7.16 - 21.0. A lower score reflects a more severe cough. In IPF subjects with available LCQ data, the T allele is observed with a frequency of 0.37 . In the IPF subjects for whom we do not have LCQ data, the T allele frequency was 0.33 .

\section{Associations with LCQ}

Table 3 presents results of the full model, controlling for age, gender, GERD status, UACS status, percent predicted FVC, DLCO, smoking status, sleep apnea, ACE-I use for patients with IPF. Cough intensity as measured by the LCQ was significantly related to the $\mathrm{T}$ allele status, age, ACE inhibitor use; all other covariates were not significant. We see a significant association between the genotype and the presence of cough.

\begin{tabular}{|c|c|c|c|}
\hline Variable & $\begin{array}{l}\text { Number of } \\
\text { subjects }\end{array}$ & Mean (SD) & Range \\
\hline Age & 68 & $74.41(8.05)$ & $46.13-93.17$ \\
\hline FVC (percent predicted) & 62 & $72.57(20.43)$ & $30-118$ \\
\hline FEV1/FVC ratio & 62 & $79.79(6.04)$ & $65.79-94.56$ \\
\hline DLCO & 54 & $43.07(15.08)$ & $12-75$ \\
\hline LCQ physical & 68 & $5.24(1.10)$ & $2.75-7.0$ \\
\hline LCQ psychological & 68 & $5.46(1.38)$ & $2.0-7.0$ \\
\hline LCQ Social & 68 & $5.46(1.35)$ & $2.0-7.0$ \\
\hline LCQ Total & 68 & $16.16(3.66)$ & $7.16-21.0$ \\
\hline
\end{tabular}

FVC $=$ forced Vital Capacity.

FEV1/FVC ratio = Forced Expiratory Volume in one second/forced vital capacity $\mathrm{LCQ}=$ Leicester Cough Questionnaire.

\section{Discussion}

In our cohort of 68 IPF patients, we replicate the reported association between the minor $\mathrm{T}$ allele of SNP rs35705950 in the MUC5B promoter region and ILD. Our data demonstrate a minor allele frequency (MAF) of $37 \%$ in the group with LCQ and 33\% in the group without the LCQ, similar to previously published IPF data $[1,12]$. Seibold et al. [1], reported a MAF of $37.5 \%$ in cases and $9.1 \%$ in controls. Data from the $1000 \mathrm{Ge}-$ nomes Project gives a frequency of the $\mathrm{T}$ allele of $5.1 \%$ for controls. Our study is therefore consistent with the current observations that the minor allele is associated with IPF.

Within the subset of patients for whom we have data on cough severity, we found statistically significant association of the minor $\mathrm{T}$ allele with cough severity. This association is independent of effects of age, gender and other clinical variables (GERD, UACS, smoking status, sleep apnea, FVC, FEV1/FVC and DLCO). This lack of association with the FEV1/FVC ratio and DLCO suggests that concomitant emphysema or other obstructive disease does not account for any of the observed cough differences. There were an additional 68 patients who did not return the cough questionnaire. This is in part because 45 of these patients had died prior to the initiation of this study. It is notable that this group matches the questionnaire group in age, sex and genotype frequency. However, the pulmonary function was significantly lower, likely related to the late phase of their disease at the time of recruitment. The IPF subjects demographics are consistent with the current literature in that they were predominantly male and older in age. Of note, our population does have a smaller percentage of smokers than is typically reported. This reflects the population of Utah where smoking is less common.

There are several possible mechanisms for our observation that MUC5B genetic variation is related to cough severity. MUC5B expression is upregulated in patients with IPF who carry the minor allele [1]. The upregulation may impact airway clearance of mucus or increase mucus secretion resulting in a symptomatic cough. Murine models suggest that quantities of intracellular mucin in airway epithelial cells results from the balance between mucin production, clearance and secretion. This balance is tightly controlled by MUC5AC and MUC5B [13]. In normal airways, MUC5B appears to be the primary gel forming mucin in the small airways. Expression of both of these mucins can be altered by several inflammatory factors [14] although it appears that MUC5B expression is less influenced in inflammatory states than is MUC5AC [15].

The MUC5B polymorphism relationship to cough in IPF observed in our study may be consistent with recent findings by Seibold et al. [16] demonstrating that MUC5B 
Table 3 Association in the subset of 68 subjects with IPF between MUC5B and LCQ scales using full and parsimonious General Linear Models

\begin{tabular}{|c|c|c|c|c|c|c|}
\hline Variable & $\begin{array}{l}\text { Independent effect } \\
\text { of } T \text { allele: } F \text { ( } p \text {-value) }\end{array}$ & $\begin{array}{l}\text { Independent effect } \\
\text { of age: } F \text { ( } p \text {-value) }\end{array}$ & $\begin{array}{l}\text { Independent effect } \\
\text { of ACE: } F \text { ( } p \text {-value) }\end{array}$ & $\begin{array}{l}\text { Least squares } \\
\text { mean for GG } \\
\text { genotype }\end{array}$ & $\begin{array}{l}\text { Least squares } \\
\text { mean for GT } \\
\text { and TT genotypes }\end{array}$ & $\begin{array}{l}\text { Variance } \\
\text { explained }\left(R^{2}\right)\end{array}$ \\
\hline \multicolumn{7}{|c|}{ Full model $(\mathrm{N}=58)$} \\
\hline Physical & $5.37(0.03)$ & $6.06(0.02)$ & $3.58(0.06)$ & 4.55 & 5.32 & $31.87 \%$ \\
\hline Psychological & $11.98(0.001)$ & $10.77(0.002)$ & $4.70(0.04)$ & 4.14 & 5.51 & $40.34 \%$ \\
\hline Social & $11.83(0.001)$ & $11.52(0.001)$ & $3.76(0.06)$ & 4.46 & 5.76 & $42.18 \%$ \\
\hline Total LCQ & $10.85(0.002)$ & $10.60(0.002)$ & $4.51(0.04)$ & 13.15 & 16.59 & $40.24 \%$ \\
\hline \multicolumn{7}{|c|}{ Parsimonious model $(\mathrm{N}=67)$} \\
\hline Physical & $6.24(0.02)$ & $8.12(0.006)$ & $3.94(0.05)$ & 5.00 & 5.70 & $18.58 \%$ \\
\hline Psychological & $9.53(0.003)$ & $9.59(0.003)$ & $6.12(0.02)$ & 5.10 & 6.15 & $23.80 \%$ \\
\hline Social & $12.80(0.007)$ & $14.35(0.003)$ & $4.67(0.04)$ & 4.96 & 6.11 & $28.32 \%$ \\
\hline Total LCQ & $10.56(0.002)$ & $11.83(0.001)$ & $5.50(0.02)$ & 15.07 & 17.95 & $25.68 \%$ \\
\hline
\end{tabular}

Note. Effects of covariates are only noted when they were found to be significant.

Full Model controlled for age, gender, \% predicted FVC, GERD status, UACS status, smoking status (yes/no), sleep apnea (yes/no), IPF vs. related diagnosis, and ACE inhibitor (yes/no) ( $\mathrm{N}=58$ due to missing data for the secondary predictors). Only significant predictors are listed.

Parsimonious Model controlled only for significant predictors in the full model: age, gender and ACE inhibitor (yes/no) $(\mathrm{N}=67)$.

is the dominant mucin in the normal distal airway epithelium and in the honeycomb lesion seen in IPF [16]. Mucin may be developing distally in those patients with overexpression driven by the MUC5B mutations. Distal mucin accumulation may trigger a cough that may or may not be productive. This phenomenon is postulated in other diseases such as asthma, bronchiolitis and emphysema where the presence of excess mucus from the surface epithelium primarily impacts the distal airways [17]. The previous study by Siebold suggested that mucus production is enhanced in all patients with IPF regardless of the MUC5B genotype $[1,18]$. However, MUC5B is the overexpressed mucin in these patients and may possess specific qualities that trigger an exaggerated cough. Interestingly, in our study, the MUC5B polymorphism did not appear to impact sinus disease suggesting there is no role of this genetic variant in upper airway tract disease.

The presence of the minor $(\mathrm{T})$ allele has been associated with improved survival in IPF [18]. This finding supports the genetic basis of disease heterogeneity associated with the MUC5B genotype. The presence of cough would be expected to increase shear stress postulated to be a factor in IPF [19] and thus, from a biomechanical perspective, it is difficult to reconcile increased cough and improved survival. While it is not immediately apparent how an enhanced cough and improved survival are interrelated, it could be postulated that the cough encourages clearance of infectious agents or decreases time of exposure to excess MUC5B and other deleterious molecules in the respiratory bronchioles that potentially interfere with alveolar repair.

This study has a number of limitations. The number of patients who responded to the questionnaire is relatively small, mostly reflective of the death of subjects who were accrued in earlier years prior to the current study with the cough questionnaire. For these subjects, descriptive information including sinus disease, acid reflux disease or estimates of cough severity on subjects are not uniformly available. Thus, although the genotype frequencies were similar in subjects with and without cough questionnaires, we do not know if this group's cough severity has any relation to the $\mathrm{T}$ allele. A second limitation is that our measure of cough was a self-report rather than an objective cough count. This methodology may introduce some reporter bias. However, it should be noted that a well-accepted validated questionnaire was utilized. Our analysis of the comorbidities known to impact cough is suboptimal. Subjects were assigned a categorization of affectation by self-report and medical record review when available. In the case of GERD, current estimates that up to $90 \%$ of patients with idiopathic pulmonary fibrosis have GERD [20]. Our reported percentage of GERD likely underestimates true prevalence of the GERD in our subjects. Moreover, we do not have validated data quantifying the severity of reflux or the effectiveness of treatment. Future studies to follow up on our observation would benefit from a larger study population, more precise measures of the comorbidities known to produce cough and an objective cough measure. In addition, evaluating the relationship between the MUC5B polymorphism and the Cough Quality of Life questionnaire, which has recently been validated for use in IPF [21], should be considered. Evaluation of the association between mucus characteristics, MUC5B allele and cough severity might also be interesting.

The variable expression of cough in IPF patients is not predictable. Cough is a problematic symptom in many, but not all, patients with this disease. While well-known 
cough risk factors such as GERD or ACE inhibitors can sometimes be controlled, clinicians are often unsuccessful in mitigating this troubling symptom. Recently, use of thalidomide has been shown to decrease cough severity in IPF [22], but there are very few effective therapeutic options for treating cough. Understanding genetic underpinnings of this and other specific clinical features of IPF may allow for personalized therapeutic approaches with potential to improve cough or even slow disease progression.

Our findings represent a potentially important application of the role MUC5B plays in the phenotypic expression of IPF. Phenotypic heterogeneity is observed clinically in patients with IPF but the genetic components of this heterogeneity are not understood. As further genetic contributions to IPF are elucidated, it is important to determine the associations between genotypes and phenotypic expression. Our observation of the possible relationship between MUC5B and cough suggests a possible influence of this polymorphism and suggests that the presence of the minor allele in MUC5B may account for a specific phenotypic component of IPF.

\section{Competing interests}

The authors declare that they have no competing interests.

\section{Authors' contributions}

MBS was responsible overseeing all aspects of the study and is the guarantor of the manuscript. M.B.S, RKW, HC, and designed the research; MBS, MW, SW, PC and NS collected the data; $\mathrm{HC}$ and RW analyzed the data; RW performed the sequencing; MBS, RKW, HC, PC and KS wrote the paper. All authors read and approved the final manuscript.

\section{Acknowledgements}

MBS is supported by the Program in Personalized Health Care, University of Utah. Funding provided by Program in Personalized Medicine, University of Utah, Human DNA Sequencing Grant Program.

\section{Author details}

'Division of Pulmonary Medicine, Department of Internal Medicine, University of Utah School of Medicine, 420 Chipeta Way, Suite 2020, Salt Lake City, UT 84108, USA. ${ }^{2}$ Division of Clinical Epidemiology, Department of Internal Medicine, University of Utah School of Medicine, Salt Lake City, Utah, USA. ${ }^{3}$ Division of Pulmonary Medicine, Department of Internal Medicine, Intermountain Medical Center, Salt Lake City, Utah, USA. ${ }^{4}$ University of Montana, Missoula, MT, USA. ${ }^{5}$ Department of Psychiatry, University of Utah School of Medicine, Salt Lake City, Utah, USA.

Received: 2 October 2013 Accepted: 26 February 2014 Published: 25 March 2014

\section{References}

1. Seibold MA, Wise AL, Speer MC, Steele MP, Brown KK, Loyd JE, Fingerlin TE, Zhang W, Gudmundsson G, Groshong SD, Evans CM, Garantziotis S, Adler KB, Dickey BF, du Bois RM, Yang IV, Herron A, Kervitsky D, Talbert JL, Markin C, Park J, Crews AL, Slifer SH, Auerbach S, Roy MG, Lin J, Hennessy CE, Schwarz MI, Schwartz DA: A common MUC5B promoter polymorphism and pulmonary fibrosis. N Engl J Med 2011, 364(16):1503-1512. doi:10.1056/NEJMoa1013660[published Online First: Epub Date]|.

2. Ryerson CJ, Abbritti M, Ley B, Elicker BM, Jones KD, Collard HR: Cough predicts prognosis in idiopathic pulmonary fibrosis. Respirology 2011, 16(6):969-975. doi:10.1111/j.1440-1843.2011.01996x.xpublished Online First: Epub Date].
3. Brown KK: Chronic cough due to chronic interstitial pulmonary diseases: ACCP evidence-based clinical practice guidelines. Chest 2006, 129(1 Suppl):180S-185S. doi:10.1378/chest.129.1_suppl.180S[published Online First: Epub Date].

4. Madison JM, Irwin RS: Chronic cough in adults with interstitial lung disease. Curr Opin Pulm Med 2005, 11(5):412-416. doi:00063198-200509000-00011.

5. Hope-Gill BD, Hilldrup S, Davies C, Newton RP, Harrison NK: A study of the cough reflex in idiopathic pulmonary fibrosis. Am J Respir Crit Care Med 2003, 168(8):995-1002. doi:10.1164/rccm.200304-5970C[published Online First: Epub Date]|.

6. Lalloo UG, Lim S, DuBois R, Barnes PJ, Chung KF: Increased sensitivity of the cough reflex in progressive systemic sclerosis patients with interstitial lung disease. Eur Respir J 1998, 11(3):702-705.

7. Raghu G, Collard HR, Egan JJ, Martinez FJ, Behr J, Brown KK, Colby TV, Cordier JF, Flaherty KR, Lasky JA: An official ATS/ERS/JRS/ALAT statement: idiopathic pulmonary fibrosis: evidence-based guidelines for diagnosis and management. Am J Respir Crit Care Med 2011, 183(6):788-824. doi:10.1164/rccm.2009-040GL[published Online First: Epub Date]|.

8. American Thoracic Society/European Respiratory Society International Multidisciplinary Consensus Classification of the Idiopathic Interstitial Pneumonias: This joint statement of the American Thoracic Society (ATS), and the European Respiratory Society (ERS) was adopted by the ATS board of directors, June 2001 and by the ERS Executive Committee, June 2001. Am J Respir Crit Care Med 2002, 165(2):277-304.

9. Birring SS, Prudon B, Carr AJ, Singh SJ, Morgan MD, Pavord ID: Development of a symptom specific health status measure for patients with chronic cough: Leicester Cough Questionnaire (LCQ). Thorax 2003, 58(4):339-343

10. Miller MR, Hankinson J, Brusasco V, Burgos F, Casaburi R, Coates A, Crapo R, Enright $\mathrm{P}$, van der Grinten $\mathrm{CP}$, Gustafsson $\mathrm{P}$, Jensen R, Johnson DC, Maclntyre N, McKay R, Navajas D, Pedersen OF, Pellegrino R, Viegi G, Wanger J, ATS/ERS Task Force: Standardisation of spirometry. Eur Respir J 2005, 26(2):319-338.

11. Chatterjee SHA: Regression Analysis by Example. Hoboken, New Jersey: John Wiley \& Sons; 2000

12. Zhang Y, Noth I, Garcia JG, Kaminski N: A variant in the promoter of MUC5B and idiopathic pulmonary fibrosis. N Engl I Med 2011, 364(16):1576-1577. doi:10.1056/NEJMc1013504[published Online First: Epub Date].

13. Evans CM, Kim K, Tuvim MJ, Dickey BF: Mucus hypersecretion in asthma: causes and effects. Curr Opin Pulm Med 2009, 15(1):4-11. doi:10.1097/ MCP.0b013e32831da8d3[published Online First: Epub Date]|

14. Zhen G, Park SW, Nguyenvu LT, Rodriguez MW, Barbeau R, Paquet AC, Erle DJ: IL-13 and epidermal growth factor receptor have critical but distinct roles in epithelial cell mucin production. Am J Respir Cell Mol Biol 2007, 36(2):244-253. doi:10.1165/rcmb.2006-01800C[published Online First: Epub Date]|.

15. Evans CM, Koo JS: Airway mucus: the good, the bad, the sticky. Pharmacol Ther 2009, 121(3):332-348. doi:10.1016/.jpharmthera.2008.11.001[published Online First: Epub Date].

16. Seibold MA, Smith RW, Urbanek C, Groshong SD, Cosgrove GP, Brown KK, Schwarz MI, Schwartz DA, Reynolds SD: The idiopathic pulmonary fibrosis honeycomb cyst contains a mucocilary pseudostratified epithelium. PloS One 2013, 8(3):e58658. doi:10.1371/journal.pone.0058658[published Online First: Epub Date].

17. Williams OW, Sharafkhaneh A, Kim V, Dickey BF, Evans CM: Airway mucus: From production to secretion. Am J Respir Cell Mol Biol 2006, 34(5):527-536. doi:10.1165/rcmb.2005-0436SF[published Online First: Epub Date].

18. Pelito AL, Zhang Y, Fingerlin TE, Ma SF, Garcia JG, Richards TJ, Silveira $L$, Lindell KO, Steele MP, Loyd JE, Gibson KF, Seibold MA, Brown KK, Talbert JL, Markin C, Kossen K, Seiwert SD, Murphy E, Noth I, Schwarz MI, Kaminski N, Schwartz DA: Association between the MUC5B promoter polymorphism and survival in patients with idiopathic pulmonary fibrosis. JAMA 2013:1-8. doi: 10.1001/jama.2013.5827[published Online First: Epub Date]].

19. Leslie KO: Idiopathic pulmonary fibrosis may be a disease of recurrent, tractional injury to the periphery of the aging lung: a unifying hypothesis regarding etiology and pathogenesis. Arch Pathol Lab Med 2012, 136(6):591-600. doi:10.5858/arpa.2011-0511-OA[published Online First: Epub Date].

20. Raghu G, Freudenberger TD, Yang S, Curtis JR, Spada C, Hayes J, Sillery JK, Pope CE 2nd, Pellegrini CA: High prevalence of abnormal acid gastro- 
oesophageal reflux in idiopathic pulmonary fibrosis. Eur Respir J 2006, 27(1):136-142. doi:10.1183/09031936.06.00037005[published Online First: Epub Date].

21. Lechtzin N, Hilliard ME, Horton MR: Validation of the cough quality of life questionnaire in patients with idiopathic pulmonary fibrosis. Chest 2013. doi:10.1378/chest.12-2870[published Online First: Epub Date].

22. Horton MR, Santopietro V, Mathew L, Horton KM, Polito AJ, Liu MC, Danoff SK, Lechtzin $\mathrm{N}$ : Thalidomide for the treatment of cough in idiopathic pulmonary fibrosis: a randomized trial. Ann Intern Med 2012, 157(6):398-406. doi:10.7326/0003-4819-157-6-201209180-00003[published Online First: Epub Date].

doi:10.1186/1745-9974-10-3

Cite this article as: Scholand et al: Severity of cough in idiopathic pulmonary fibrosis is associated with MUC5 B genotype. Cough 2014 10:3.

\section{Submit your next manuscript to BioMed Central and take full advantage of:}

- Convenient online submission

- Thorough peer review

- No space constraints or color figure charges

- Immediate publication on acceptance

- Inclusion in PubMed, CAS, Scopus and Google Scholar

- Research which is freely available for redistribution 